\title{
Pathogenetic factors involved in recurrent pregnancy loss from multiple aspects
}

\author{
Chang-Zhu Pei ${ }^{1}$, Young Ju Kim² ${ }^{2}$ Kwang-Hyun Baek ${ }^{1}$ \\ 'Department of Biomedical Science, CHA University, CHA General Hospital, Seongnam; 'Department of Obstetrics and Gynecology, Ewha Womans \\ University College of Medicine, Seoul, Korea
}

Recurrent pregnancy loss (RPL) is a common complication in obstetrics, affecting about $5 \%$ of women of childbearing age. An increase in the number of abortions results in escalation in the risk of miscarriage. Although concentrated research has identified numerous causes for RPL, about $50 \%$ of them remain unexplained. Pregnancy is a complex process, comprising fertilization, implantation, organ and tissue differentiation, and fetal growth, which is effectively controlled by a number of both maternal and fetal factors. An example is the immune response, in which $\mathrm{T}$ cells and natural killer cells participate, and inflammation mediated by tumor necrosis factor or colony-stimulating factor, which hinders embryo implantation. Furthermore, vitamin D affects glucose metabolism and inhibits embryonic development, whereas microRNA has a negative effect on the gene expression of embryo implantation and development. This review examines the causes of RPL from multiple perspectives, and focuses on the numerous factors that may result in RPL.

Keywords: Proteomics; Recurrent miscarriage; Vitamin D

\section{Introduction}

Recurrent pregnancy loss (RPL) is defined as the occurrence of 2 or 3 consecutive abortions prior to the 20th week of pregnancy $[1,2]$. The incidence of RPL is about $1-2 \%$, affecting $5 \%$ of families who want to have a child [2]. So far, the known pathogenesis of RPL comprises only $50 \%$ of the causes, which include immune factors, endocrine factors, genetic factors, infection factors, metabolic abnormalities, anatomic abnormalities, and other unexplained factors [3]. We speculate that RPL results from various interactions of the aforementioned factors. At least $50 \%$ of patients who have undergone a complete evaluation remain clueless as to why they are unable to achieve pregnancy $[3,4]$. A comprehensive understanding of all possible causes of RPL is necessary, and in the current study, various methods have been applied to gather relevant information. This review focuses on the role of immune response, infection factors, growth factors, and vitamin D, and evaluates the application of proteomics and microRNA (miRNA) analyses in RPL pathogenesis.

\section{Etiological factors for recurrent pregnancy loss with the perspective of proteomics}

Proteomics is a useful tool for recognizing altered protein expression, as well as proteins involved in disease pathogenesis [5]. In a previous study, we applied 2-dimensional-gelbased proteomic tools and identified, for the first time, RPLassociated proteins in the follicular fluid of RPL patients [6]. Our results indicated that coagulation factors (fibrinogen $\gamma$ and antithrombin) play an important role in maintaining

Received: 2018.12.27. Revised: 2019.02.23. Accepted: 2019.05.06. Corresponding author: Kwang-Hyun Baek

Department of Biomedical Science, CHA University, CHA General Hospital, 335 Pangyo-ro, Bundang-gu, Seongnam 13488, Korea

E-mail: baek@cha.ac.kr

https://orcid.org/0000-0001-7662-7190

Articles published in Obstet Gynecol Sci are open-access, distributed under the terms of the Creative Commons Attribution Non-Commercial License (http://creativecommons. org/licenses/by-nc/3.0/) which permits unrestricted non-commercial use, distribution, and reproduction in any medium, provided the original work is properly cited.

Copyright $\odot 2019$ Korean Society of Obstetrics and Gynecology 


\section{Obstetrics \& Gynecology Science}

Chang-Zhu Pei, et al. Pathogenetic factors with RPL

normal pregnancy [6]. To conduct a comparative proteomic study, blood samples from normal and RPL patients were analyzed in a later study, and these results suggested that inter-a-trypsin inhibitor heavy chain family member 4 expression is a useful biomarker $[7,8]$. In a recent study, Pan et al. [5] analyzed placenta samples from normal and RPL patients and found 314 differentially expressed proteins, all playing important roles in the growth of the embryo. Furthermore, a network analysis demonstrated that angiotensinogen affects embryonic development via the rennin-angiotensin system [9]. In addition, mitogen-activated protein kinase 14 (MAPK14) is involved in the MAPK singnaling pathway, which in turn mediates embryonic responses and apoptosis [10]. Defects in prothrombin (F2) are a cause of thrombosis (THR) susceptibility, and THR can result in RPL [11]. Other proteins include lamin B1 (involved in the development and nuclear integrity of the mouse) [12], nuclear autoantigenic sperm protein (required for preimplantation development during the blastocyst stage in cattle) [13], and secreted protein acidic and rich in cysteine (SPARC). SPARC is a matricellular glucoprotein that promotes cardiomyocyte differentiation by promoting the expression of bone morphogenetic protein 2 (BMP2), and is an essential auxiliary factor for the up-regulation of NKX2.5 expression in cardiomyocytes, mediated by BMP2 [14].

Parietal endoderm-secreted S100A4 is a calcium-binding protein belonging to the EF-hand family. In vitro studies have shown that it influences early cardiomyocyte differentiation and proliferation by increasing NKX2.5, mef2C, and mhca expression [15]. RNA polymerase II prolonged by the yeast transcription-export (TREX) complex promotes gene expression by combining RNA processing factor and nuclear RNA output factor [16]. TREX consists of THO subcomplexes containing Hpr1p, Tho $2 p$, Mft $1 p$, and Thp2p proteins [17]. The functional linear homogen of Hpr1p in metazoa are Thoc1, Hpr1p, or p84 [18]. Thioredoxins are small redox proteins that regulate the activities of nuclear factor (NF)- $\mathrm{kB}$ and activator protein 1 , mediate the antioxidant properties of peroxidase, and participate in early embryo formation [19]. Fibronectin and vitronectin are extracellular matrix protein components that promote the endoderm differentiation of human embryonic stem cells through interaction with integrin a5 and integrin a [20].

\section{DNA methylation in recurrent pregnancy loss}

Epigenetics and epigenetic research are involved in investigating hereditary gene expression or cell phenotype alterations through certain mechanisms, without changing the DNA sequence [21]. DNA methylation is one of the major epigenetic modifications, and plays important roles in embryonic implantation and development [22]. Abnormal DNA methylation is associated with miscarriage, preeclampsia, abnormal embryonic development, and birth abnormalities [23-26]. Among the 539 differential methylation regions (DMRs) found in RPL patients, p53 and SP transcription factors are recruited in the CAMP-responsive element binding protein 5 (CREB5) DMR by CREB5 hypomethylation, which subsequently increases CREB5 expression [27]. Notably, knock-down of CREB5 results in increased levels of tumor necrosis factor (TNF)- $a$ and decreased levels of interleukin (IL)-10, and enhances the expression of NF-kB and p-NF-kB in monocytes, thereby causing immunosuppression [28]. In addition, CREB5 methylation and expression are regulated by IL-6 levels [29]. CREB5 also plays a key role in RPL pathogenesis. Forkhead Box P3 (FOXP3), specifically expressed in $\mathrm{CD} 4^{+} \mathrm{CD} 25^{+} \mathrm{T}$ cells, is a human transcription regulator [30], and high expression levels of the FOXP3 gene are key to the development and function of Treg cells [31]. Methylation levels of the FOXP3 promoter were reported to be higher in patients with RPL than in the control group, and conversely, FOXP3 protein levels were found to be lower in the RPL group than in the control group. The effect of FOXP3 on the differentiation of T-reg cells is the probable cause of immune tolerance failure and subsequent RPL [32].

\section{Novel genes and mutations in recurrent pregnancy loss}

Since innumerable genes are involved at every physiological step to ensure successful mammalian reproduction, mutations could be the causative factors of the molecular etiology of RPL [33,34]. Quintero-Ronderos et al. [35] reported that 27 coding variants in 22 genes are potentially related to the phenotype resulting in RPL. The 27 coding variants are associated with biological processes involved in cell adhesiontrophoblast endometrium interaction (TRO, CDH11, and CDH1), coagulation (THBD, F5, and FGA), extracellular matrix 


\title{
Obstetrics \& Gynecology Science
}

\author{
Vol. 62, No. 4, 2019
}

remodeling (MMP10, MMP9, COL6A3, ADAMTS1, and TNC), angiogenesis (FLT1 and EPAS1), cell proliferation, differentiation, migration, apoptosis (LIFR, FGFR2, and BMP7), metabolism $(A M N)$, immunological function modulation (IDO2, CR1, TLR3, and TRAF3IP1), and steroidal nuclear receptor activation (NCOA1) [35]. Nitric oxide is a transient gaseous lipophilic molecule, which has a variety of physiological regulatory functions in reproductive regulation. It plays important roles in oviductal functions, trophoblast invasion, trophoblast differentiation, blastocyst implantation, ovulation, fetal-maternal circulatory system establishment, and uterine blood flow regulation $[36,37]$. Shin et al. [38] reported that eNOS gene polymorphisms, variable number tandem repeat in intron 4, $-786 \mathrm{~T}>\mathrm{C}$, and 894G $>\mathrm{T}$, are associated with risk of RPL. Azani et al. [39] reported that the eNOS -786C-4a-894G haplotype and $-786 \mathrm{~T}>\mathrm{C}$ polymorphism are associated with high risk of RPL. Through next generation sequencing analysis, Ryu et al. [40] found that the combination of stop-gain polymorphism OR4C16G>A and A-A (TAS2R46 and OR4C 16) alleles was strongly associated with RPL prevalence.

\section{Immune response in recurrent pregnancy loss}

Embryos express paternal antigens that are foreign to the mother and may therefore be viewed as allografts [41]. Hence, the immune response of a pregnant woman plays a critical role in maintaining the pregnancy [42]. Immune responses in RPL are mainly divided into immune suppression and immune tolerance $[41,43]$. Antigens expressed on the surface of fetal or placental tissues possibly induce alloimmune responses by the mother, along with certain immunologic mechanisms that sustain the continuation of normal pregnancy. Type $1 \mathrm{~T}$ helper (Th1) and type $2 \mathrm{~T}$ helper (Th2) cells play important roles in immune responses, particularly in immune rejection and tolerance $[43,44]$. Based on a previous report, the normal range of the Th1/Th2 cell ratio should be less than 10.3 [45]. Moreover, Th2 cell dominance is important for the maintenance of normal pregnancy. Ota et al. [46] found that vitamin D deficiency increases the risk of RPL by promoting cellular immunity and autoimmunity. Vitamin $D$ deficiency increases the expression levels of $C D 19^{+} B$ cells, $\mathrm{CD}_{56}{ }^{+}$natural killer (NK) cells, Th1/Th2 ratio, NK cell cytotoxicity, and the presence of various autoantibodies in the peripheral blood [46]. Wegmann [47] proposed an immunotrophic theory wherein some cytokines are produced by maternal cells, which recognize the fetal antigens, promote proliferation of trophoblastic cells, and help in sustaining the pregnancy. Li et al. [48] reported that signaling by the T cell immunoglobulin (type I membrane protein) and mucin-containing protein 3 (Tim-3) in natural NK cells has an essential protective role. The number of Tim- $3^{+}$pNK cells (peripheral NK cells) transiently increased during the first trimester of pregnancy, as compared with Tim- $3^{-}$NK cells [48]. Tim- $3^{+} \mathrm{NK}$ cells display immunosuppressive activity during early pregnancy by producing increased levels of anti-inflammatory cytokines, including transforming growth factor (TGF)- $\beta 1$, IL$10, I L-4$, and decreased pro-inflammatory cytokines, including TNF-a [48]. Tim-3 on NK cells is stimulated by its ligand galectin-9, leading to activation of signaling by the kinases (c-Jun N-terminal kinase [JNK] and protein kinase B). The abundance of Tim-3 on the surface of NK cells is enhanced through IL-4-signal transducer and activator of transcription 6 or progesterone signaling. Furthermore, the Tim-3 blockade disrupts immune tolerance and induces pregnancy failure (Fig. 1) [48]. Human amniotic epithelial cells play a

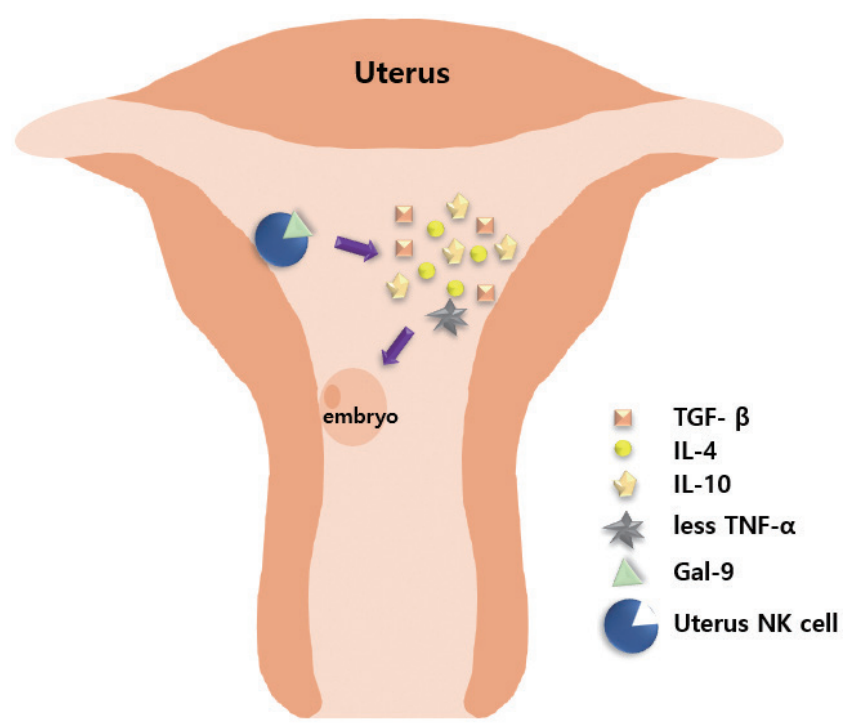

Fig. 1. Role of natural killer (NK) cells in creating a supporting environment for embryo implantation. T cell immunoglobulin (type I membrane protein) and mucin-containing protein $3^{+}$uterine NK cells combine with ligand galectin-9 (Gal-9) to secrete interleukin (IL)-4, transforming growth factor (TGF)- $\beta$, IL-10, with decreased production of tumor necrosis factor (TNF)- $a$, thereby inducing immune suppression and tolerance, and creating an environment conducive to embryo implantation. 


\section{Obstetrics \& Gynecology Science}

Chang-Zhu Pei, et al. Pathogenetic factors with RPL

potent regulatory role in the immune response by reducing TGF- $\beta$ production and regulating the secretion of interferon (IFN) and IL-17 by T cells [49].

In autoimmune diabetes, it is generally believed that destruction of inflammatory $\beta$ cells in the pancreas is due to the involvement of autoreactive T cells [50]. The chronic inflammation of pancreatic islets plays a critical role in disease development, and immune responses are the millstones in the mechanism of endothelial activation and atherosclerosis plaque development. This is demonstrated by the correlation between inflammatory marker levels and the risk of circulatory events in patients with diabetes mellitus (DM) [51]. Autoimmune antibodies and metabolic abnormalities are known to trigger RPL [50]. A slowly progressive form of type 2 diabetes, latent autoimmune diabetes in adults (LADA), has a prevalence rate of about $10-15 \%$ in patients diagnosed with type 2 diabetes [50]. Small studies have described that abnormal DNA methylation of CD4 T cells [52], T-reg cells [53], and NK cells [54] leads to loss of function of the pancreatic $\beta$ cells by LADA, and this abnormal glucose metabolism eventually has adverse effects on pregnancy [50]. The glutamic acid decarboxylase (GAD) antibody is an immune marker in the early stages of type 1 DM [55]. During pregnancy, routine examination of the GAD antibody can help to improve glucose metabolism and the pregnancy outcome.

\section{Cellular roles of tumor necrosis factor-a in recurrent pregnancy loss}

Formerly called cachectin, TNF-a encoded on chromosome 6 is a Th1 proinflammatory cytokine [56]. TNF-a, one of 20 genes for the HLA system, is located on chromosome 6p21.3; it spans approximately $3 \mathrm{~kb}$ and has 4 exons. More than $80 \%$ of secreted proteins are encoded by the last exon [57]. Macrophages are the primary producers of TNF-a in pregnant women, and TNF-a is involved in the signal transduction pathway in the placenta [58]. TNF-a binds to its homologous receptor TNF-R1 to release silencer of death domains and to form complexes with receptors containing the adaptor proteins TNF receptor associated factor 2, fasassociated protein with death domain, TNF receptor type 1-associated DEATH domain protein, and receptor-interacting protein [59]. These adaptor proteins then recruit additional linchpin pathway-specific enzymes (for example, IKB kinase $\beta$ and caspase-8) to the TNF-R1 complex, where they become activated and pulse-on downstream events, consequently resulting in apoptosis, JNK, and NF-KB activation [59]. In pregnancy, the immunological system plays critical roles both in the development of complications and in ensuring normal pregnancy development. A pregnancy is successful when the balance of Th1, Th2, Th17 cytokines, and T-reg cells works appropriately [60]. It is reported that TNF-a upregulates the level of programmed death-1 (PD-1) in monocytes, which binds with PD-L to promote the production of IL-10 in monocytes, and relies on IL-10 to inhibit the expansion of CD4 T cells [61]. Along with reduced IL-10 levels, TNF-a is increased throughout pregnancy and has been associated with preterm birth, miscarriages, pre-eclampsia, and fetal losses [62].

TNF-a plays a primary role in the inflammatory mechanism that regulates placentation and subsequent implantation in pregnancy outcomes. TNF- $a$ is secreted by the innate immune cells and the placental cells. An appropriate balance between Th1 (mainly TNF-a, and Th17) and Th2 cytokines (including IL-10) is essential for achieving a good obstetric outcome. Conversely, several obstetric disorders, especially RPL, may occur due to an increase in Th1-dependent cytokines, particularly TNF-a [43]. TNF-a-targeted therapies therefore constitute a promising approach in improving or curing these disorders $[63,64]$. Hence, among the new and old immunosuppressive drugs, TNF-a blockers have become an effective tool for the treatment of pregnant women presenting with inflammatory- and immune-mediated diseases. A recent study by Alijotas-Reig et al. [65] revealed neither any maternal nor fetal major adverse reactions (including fetal malformations) to TNF therapy. In fact, the incidence of fetal malformations was 3\% lower than expected.

\section{Effect of colony stimulating factor on recurrent pregnancy loss}

Colony stimulating factor (CSF)-1/M-CSF plays an important role in pregnancy. The expression of CSF-1/M-CSF significantly increases during pregnancy by 2-fold and 1,000-fold in serum and the uterus, respectively [66]. The CSF family members were detected in human cytotrophoblasts and syncytotrophoblasts of the decidual stromal cells, endometrial glands, and epithelium of the placental and maternal cells, in addition to being located on local NK cells. CSFs are 


\section{Obstetrics \& Gynecology Science}

Vol. 62, No. 4, 2019

involved in numerous reproductive functions, including ovulation, embryo implantation, placental growth, and embryo development [67]. During ovulation, CSF-3/G-CSF promotes ovulation through leukocyte attraction and activation [68]. After ovarian hyper-stimulation for in vitro fertilization, the cumulus oophorus cells synthesize and secrete CSF-1/M-CSF, and this synthesis is highly dependent on progesterone. In embryo implantation, a dominant Th-2 environment, suitable for the establishment and maintenance of a local tolerant immune environment, is required for successful implantation. CSF-3/G-CSF-mobilized Th-2 cells enhance IL-10 expression, which subsequently activates a signaling pathway leading to a dominant Th-2 environment [69]. For example, local uterine production of CSF-3/G-CSF may contribute to modulating the cytotoxicity of uterine NK cells by IFNY and IL-18 production [70]. Uterine dendritic cells (DCs) are critical for activating the $T$ cell response, thereby mediating maternal immune tolerance of the semiallogeneic fetus. Absence of GM-CSF, a known regulator of DCs, may impair the generation of T cellmediated immune tolerance at the outset of pregnancy. This may contribute to the altered DC profile and dysregulated T cell tolerance evident in infertility and miscarriage [71].

\section{Effects of sodium-glucose transport proteins on recurrent pregnancy loss}

The cloning of intestinal glucose transporter sodium-glucose transport (SGLT) 1 has been executed for over 30 years, and there have been several advances in physiological and medical research. The SLC5 gene codes for cotransporters for glucose and/or fructose (SGLT1, SGLT2, SGLT4, and SGLT5), inositol (sodium-myo-inositol co-transporter 1 [SMIT1] and SMIT2), short chain fatty acids (sodium monocarboxylate transporter 1 [SMCT1] and SMCT2), iodide (NIS), choline (choline transporter 1), and biotin (sodium dependent multivitamin transporter) [72]. The SLC5A1 gene for SGLT1 codes for a $72 \mathrm{kDa}$ protein with 14 transmembrane helices (TM[-1]1-TM13) [73]. In both humans and mice, the SGLT1 transcripts were detected in endometrial cells, especially in humans during the early to mid-luteal phase [74]. The SGLT1 gene and protein were found in mouse endometrial glandular and surface epithelial cells, but not in Sglt1-null mice. SGLT1 was functional in the mouse uterine tissue (glucoseinduced short-circuit currents), but was inactive in Sglt1-null mice [75]. Endometrial glycogen, litter size, and pup weight were all lower in the Sglt1-null mice than in wild-type mice. Similarly, in patients with RPL, the SGLT1 gene and protein expression were significantly lower during the implantation window as compared to control patients [76]. It was therefore concluded that SGLT1 deficiency in the human endometrium at implantation may predispose early pregnancy failure, obstetrical complications, and low fetal growth. Taken together, these results indicate that it may not be advisable to prescribe SGLT inhibitors to women of childbearing age.

\section{Endometritis associated with recurrent pregnancy loss}

Endometritis is subdivided into the categories of acute endometritis and chronic endometritis [77]. Acute endometritis is characterized by neutrophil infiltration into superficial endometrial epithelium, the uterine cavity, and the glandular cavity [77]. One of the pathological features of choronic endometritis is the infiltration of phasmacytes into the basal layer of the uterus [77]. Endometritis is the outcome of various endometrial structural changes, resulting in the production of numerous inflammatory cells and inflammation, thereby affecting implantation of the fertilized eggs and eventually leading to abortion [78]. Kitaya and Yasuo [79] reported that $8-28 \%$ of patients with RPL were diagnosed with chronic endometritis. However, RPL resulting from chronic endometritis can be treated, and the successful pregnancy rate and live birth rate are very high. The pregnancy rate and live birth rate are $76.3 \%$ vs. $20 \%$ and $65.8 \%$ vs. $6.6 \%$ in patients with cured and uncured chronic endometritis, respectively [80].

Metwally et al. [81] reported that obesity or being overweight is an independent factor influencing endometrial protein expression, including haptoglobin, transthyretin, and $\beta$-globulin. As an inflammatory marker, haptoglobin is an important component of the extra embryonic matrix, which may play a role in blastocyst implantation [81].

\section{Endocrine effects on recurrent pregnancy loss}

Polycystic ovary syndrome (PCOS) is a disease accompanied 


\section{Obstetrics \& Gynecology Science}

Chang-Zhu Pei, et al. Pathogenetic factors with RPL

by elevated plasma androgen levels, affecting approximately $5-10 \%$ women of childbearing age [82]. High levels of androgen result in increased abortion rates [83]. Ishikawa cells were treated with high concentrations of androgen and physiological concentrations of androgen. Eight up-regulated proteins and 10 down-regulated proteins were subsequently identified in the high androgen group. One of these proteins was the cyclin-dependent kinase inhibitor 2a; decreased levels of protein expression led to reduced Ishikawa cell migration, invasion, proliferation, and Jar spheroid attachment. These results indicate that proteins associated with PCOS may result in RPL [84]. Luteal phase deficiency (LPD) refers to the inability to maintain physiological levels of progesterone during pregnancy and to enable normal embryo implantation and growth [85]. Progesterone is secreted in a pulsating manner over a short period of time. It is therefore not possible to design an experiment to compare the level of progesterone in the blood between healthy patients and patients with RPL [86]. However, Meresman et al. [87] found that caspase-3 expression is higher in endometrial biopsy samples from women with both RPL and LPD than from women without LPD. Embryonic trophoblast cells secrete human chorionic gonadotropin (hCG), which maintains the corpus luteum function in early pregnancy and plays a key role in implantation and endometrial receptivity [88]. A retrospective cohort study reported that miscarriage rate and time to pregnancy decreased in the 45 pregnant women who underwent 135 monitored cycles without hCG support, compared to 53 pregnant women who underwent 142 cycles with a single injection of mid-luteal hCG [89].

\section{Vitamin D associated with recurrent pregnancy loss}

Vitamin $D$ is required to maintain normal human physiological activities. It affects not only bone metabolism, but also regulation of cell proliferation, differentiation, and apoptosis [90]. Vitamin D is expressed in the placenta, decidua, and ovary, and may be involved in the synthesis and secretion of hormones, thereby influencing the pregnancy outcome. Vitamin D receptor is also expressed in endometrial stromal cells and affects embryo implantation. Vitamin $D$ is a newly discovered neuroendocrine regulatory factor affecting pregnancy, which is involved in a low inflammatory response. The fact that vitamin $D$ participates in inflammation and maintains genomic stability in women is of interest $[91,92]$.

1,25(OH)2-vitamin D3 (1,25[OH]2D3), an activated vitamin $D$, inhibits the number and function of CD4 cells and induces CD8 cell expression. 1,25(OH)2D3 inhibits the proliferation of Th1 cells and suppresses the secretion of IFN- $\gamma$, IL-2, and TNF-a. In contrast, 1,25(OH)2D3 induces Th2 cells to secrete cytokines including IL-4, IL-5, IL6, IL-9, IL-10, and IL-13 [9395]. In addition, 1,25(OH)2D3 inhibits IL-6 and IL-23 secreted by Th17 cells, and promotes the differentiation and expansion of T-reg cells. Expansion factor Fox3 activates T-reg cells. 1,25(OH)2D3 inhibits the maturation and stimulation of DC cells, which negatively affects the proliferation of B cells, plasma cell differentiation, and immunoglobulin production. Thus, the abnormal immune response of maternal and fetal surfaces subsequently results in RPL (Fig. 2) [96].

\section{Cellular roles of microRNA in recurrent pregnancy loss}

The noncoding RNA molecules belonging to the miRNA family are composed of 21 to 24 nucleotides. These bind to complementary sequences on target messenger RNA, promote mRNA degradation or inhibit translation, and play a

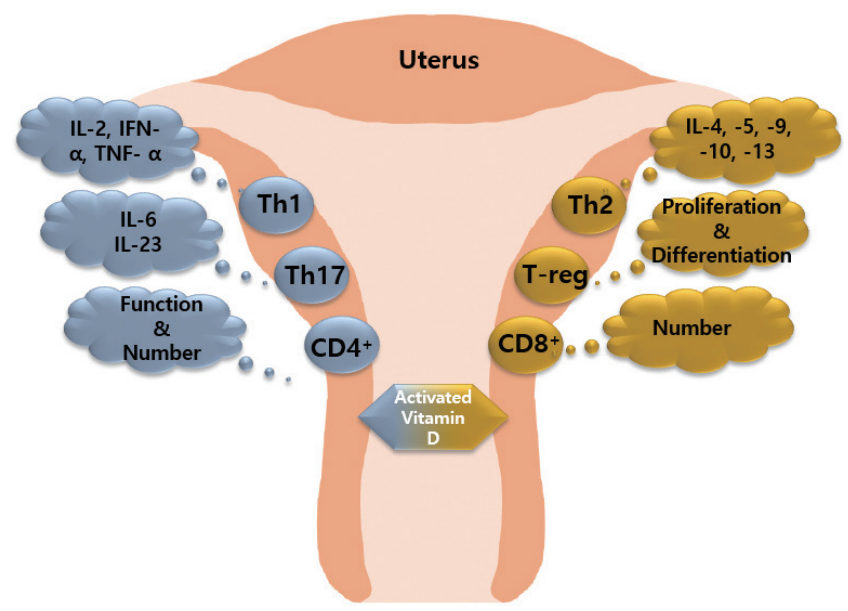

Fig. 2. Effect of activated vitamin D on immune cells. Activated vitamin D stimulates T helper (Th)2 cells to secrete anti-inflammatory factors, promotes T-reg cell differentiation and proliferation, and increases the number of $\mathrm{CD}^{+}$cells. Activated vitamin D stimulates Th1 cells and Th17 cells to secrete pro-inflammatory factors, and increase the function/number of $\mathrm{CD}^{+}$cells. TNF, tumor necrosis factor; IFN, interferon; IL, interleukin. 


\section{Obstetrics \& Gynecology Science}

Vol. 62, No. 4, 2019

negative role in gene expression $[97,98]$. More than 1,500 miRNA target more than 5,000 human genes, which may regulate normal pregnancy. Parveen and Agrawal [99] found that gene polymorphisms of miR-146aC>G (rs2910164), miR-149T>C (rs2292832), miR-196a2T>C (rs11614913), and miR-499A>G (rs3746444) are present in RPL patients. The miR-146a regulates FAS expression by binding to FAS mRNA, subsequently reducing apoptosis [100]. The increase of miR146 a levels regulated by NF- $\mathrm{KB}$ promotes the survival of mesenchymal stem cells [100]. AKT and E2F1 genes are targets of miR-149, promoting cell growth and cell cycle progression [101]. Jeon et al. [102] reported that 196a2T>C and miR499A $>\mathrm{G}$ polymorphisms may be involved in RPL.

\section{Conclusion}

This review describes the pathogenesis of RPL from multiple perspectives, such as proteomics, DNA methylation, gene mutations, the immune response, cytokines, endometritis, endocrine, vitamin D deficiency, and miRNA. Repeated abortions can occur due to a single factor in some RPL patients, while a variety of factors are involved in RPL pathogenesis. Although there are many questions that have yet to be answered, a profound understanding of the known etiological factors for RPL may provide translational implications towards therapeutic strategies.

\section{Acknowledgements}

We would like to thank the members of the Molecular Signal Transduction Laboratory at CHA University. This study was supported by the Ministry of Health \& Welfare of the Republic of Korea (Grant number, HI18C0378) through the Korea Health Industry Development Institute.

\section{Conflict of interest}

No potential conflict of interest relevant to this article was reported.

\section{References}

1. Krieg S, Westphal L. Immune function and recurrent pregnancy loss. Semin Reprod Med 2015;33:305-12.

2. Coulam CB, Clark DA, Beer AE, Kutteh WH, Silver $R$, Kwak J, et al. Current clinical options for diagnosis and treatment of recurrent spontaneous abortion. Clinical guidelines recommendation committee for diagnosis and treatment of recurrent spontaneous abortion. Am J Reprod Immunol 1997;38:57-74.

3. Practice Committee of the American Society for Reproductive Medicine. Evaluation and treatment of recurrent pregnancy loss: a committee opinion. Fertil Steril 2012;98:1103-11.

4. Practice Committee of American Society for Reproductive Medicine. Definitions of infertility and recurrent pregnancy loss: a committee opinion. Fertil Steril 2013;99:63.

5. Pan HT, Ding HG, Fang M, Yu B, Cheng Y, Tan YJ, et al. Proteomics and bioinformatics analysis of altered protein expression in the placental villous tissue from early recurrent miscarriage patients. Placenta 2018;61:1-10.

6. Kim YS, Kim MS, Lee SH, Choi BC, Lim JM, Cha KY, et al. Proteomic analysis of recurrent spontaneous abortion: identification of an inadequately expressed set of proteins in human follicular fluid. Proteomics 2006;6:3445-54.

7. Kim MS, Gu BH, Song S, Choi BC, Cha DH, Baek KH. ITI-H4, as a biomarker in the serum of recurrent pregnancy loss (RPL) patients. Mol Biosyst 2011;7:1430-40.

8. Li L, Choi BC, Ryoo JE, Song SJ, Pei CZ, Lee KY, et al. Opposing roles of inter-a-trypsin inhibitor heavy chain 4 in recurrent pregnancy loss. EBioMedicine 2018;37:535-46.

9. Tyers M, Mann M. From genomics to proteomics. Nature 2003;422:193-7.

10. Jeon YJ, Kim JH, Lee BE, Rah $H$, Shin JE, Kang $H$, et al. Association between polymorphisms in the reninangiotensin system genes and prevalence of spontaneously aborted fetuses. Am J Reprod Immunol 2013;70:238-45.

11. Bell CE, Larivière NM, Watson PH, Watson AJ. Mitogen-activated protein kinase (MAPK) pathways mediate embryonic responses to culture medium osmolarity by regulating Aquaporin 3 and 9 expression and local- 


\section{Obstetrics \& Gynecology Science}

Chang-Zhu Pei, et al. Pathogenetic factors with RPL

ization, as well as embryonic apoptosis. Hum Reprod 2009;24:1373-86.

12. Vergnes L, Péterfy M, Bergo MO, Young SG, Reue K. Lamin B1 is required for mouse development and nuclear integrity. Proc Natl Acad Sci U S A 2004;101:10428-33.

13. Nagatomo $H$, Kohri $N$, Akizawa $H$, Hoshino $Y$, Yamauchi $\mathrm{N}$, Kono $\mathrm{T}$, et al. Requirement for nuclear autoantigenic sperm protein mRNA expression in bovine preimplantation development. Anim Sci J 2016;87:45761.

14. Stary M, Pasteiner W, Summer A, Hrdina A, Eger A, Weitzer G. Parietal endoderm secreted SPARC promotes early cardiomyogenesis in vitro. Exp Cell Res 2005;310:331-43.

15. Stary M, Schneider M, Sheikh SP, Weitzer G. Parietal endoderm secreted S100A4 promotes early cardiomyogenesis in embryoid bodies. Biochem Biophys Res Commun 2006;343:555-63.

16. Wang X, Chang Y, Li Y, Zhang X, Goodrich DW. Thoc1/ $\mathrm{Hpr} 1 / \mathrm{p} 84$ is essential for early embryonic development in the mouse. Mol Cell Biol 2006;26:4362-7.

17. Chávez $S$, Beilharz T, Rondón AG, Erdjument-Bromage $H$, Tempst $P$, Svejstrup JQ, et al. A protein complex containing Tho2, Hpr1, Mft1 and a novel protein, Thp2, connects transcription elongation with mitotic recombination in Saccharomyces cerevisiae. EMBO J 2000;19:5824-34.

18. Rehwinkel J, Herold A, Gari K, Köcher T, Rode M, Ciccarelli $\mathrm{FL}$, et al. Genome-wide analysis of mRNAs regulated by the THO complex in Drosophila melanogaster. Nat Struct Mol Biol 2004;11:558-66.

19. Jakupoglu C, Przemeck GK, Schneider M, Moreno SG, Mayr N, Hatzopoulos AK, et al. Cytoplasmic thioredoxin reductase is essential for embryogenesis but dispensable for cardiac development. Mol Cell Biol 2005;25:1980-8.

20. Brafman DA, Phung C, Kumar N, Willert K. Regulation of endodermal differentiation of human embryonic stem cells through integrin-ECM interactions. Cell Death Differ 2013;20:369-81.

21. Frésard L, Morisson M, Brun JM, Collin A, Pain B, Minvielle $F$, et al. Epigenetics and phenotypic variability: some interesting insights from birds. Genet Sel Evol 2013;45:16.
22. Wu H, Zhang Y. Early embryos reprogram DNA methylation in two steps. Cell Stem Cell 2012;10:487-9.

23. Blair JD, Yuen RK, Lim BK, McFadden DE, von Dadelszen P, Robinson WP. Widespread DNA hypomethylation at gene enhancer regions in placentas associated with early-onset pre-eclampsia. Mol Hum Reprod 2013;19:697-708.

24. Feinberg AP. Phenotypic plasticity and the epigenetics of human disease. Nature 2007;447:433-40.

25. Reamon-Buettner SM, Borlak J. A new paradigm in toxicology and teratology: altering gene activity in the absence of DNA sequence variation. Reprod Toxicol 2007;24:20-30.

26. Hanna CW, McFadden DE, Robinson WP. DNA methylation profiling of placental villi from karyotypically normal miscarriage and recurrent miscarriage. Am J Pathol 2013;182:2276-84.

27. Yu M, Du G, Xu Q, Huang Z, Huang X, Qin Y, et al. Integrated analysis of DNA methylome and transcriptome identified CREB5 as a novel risk gene contributing to recurrent pregnancy loss. EBioMedicine 2018;35:334-44.

28. Long X, Li Y, Qiu S, Liu J, He L, Peng Y. MiR-582-5p/ miR-590-5p targeted CREB1/CREB5-NF-kB signaling and caused opioid-induced immunosuppression in human monocytes. Transl Psychiatry 2016;6:e757.

29. Nevalainen $T$, Kananen $L$, Marttila $S$, Jylhä M, Hervonen A, Hurme $M$, et al. Transcriptomic and epigenetic analyses reveal a gender difference in agingassociated inflammation: the vitality $90+$ study. Age (Dordr) 2015;37:9814.

30. Williams LM, Rudensky AY. Maintenance of the Foxp3dependent developmental program in mature regulatory $T$ cells requires continued expression of Foxp3. Nat Immunol 2007;8:277-84.

31. Wan YY, Flavell RA. Regulatory T-cell functions are subverted and converted owing to attenuated Foxp3 expression. Nature 2007;445:766-70.

32. Hou W, Li Z, Li Y, Fang L, Li J, Huang J, et al. Correlation between protein expression of FOXP3 and level of FOXP3 promoter methylation in recurrent spontaneous abortion. J Obstet Gynaecol Res 2016;42:1439-44.

33. Cha J, Sun X, Dey SK. Mechanisms of implantation: strategies for successful pregnancy. Nat Med 2012;18:1754-67. 


\section{Obstetrics \& Gynecology Science}

Vol. 62, No. 4, 2019

34. White MD, Plachta N. How adhesion forms the early mammalian embryo. Curr Top Dev Biol 2015;112:117.

35. Quintero-Ronderos P, Mercier E, Fukuda M, González R, Suárez CF, Patarroyo MA, et al. Novel genes and mutations in patients affected by recurrent pregnancy loss. PLoS One 2017;12:e0186149.

36. Sladek SM, Magness RR, Conrad KP. Nitric oxide and pregnancy. Am J Physiol 1997;272:R441-63.

37. Suryanarayana $V$, Rao L, Kanakavalli M, Padmalatha $V$, Deenadayal $M$, Singh $L$. Recurrent early pregnancy loss and endothelial nitric oxide synthase gene polymorphisms. Arch Gynecol Obstet 2006;274:119-24.

38. Shin SJ, Lee HH, Cha SH, Kim JH, Shim SH, Choi DH, et al. Endothelial nitric oxide synthase gene polymorphisms (-786T>C, 4a4b, 894G>T) and haplotypes in Korean patients with recurrent spontaneous abortion. Eur J Obstet Gynecol Reprod Biol 2010;152:64-7.

39. Azani A, Hosseinzadeh A, Azadkhah R, Zonouzi AA, Zonouzi $A P, A f t a b i ~ Y$, et al. Association of endothelial nitric oxide synthase gene variants $(-786 \mathrm{~T}>\mathrm{C}$, intron 4 b/a VNTR and 894 G>T) with idiopathic recurrent pregnancy loss: a case-control study with haplotype and in silico analysis. Eur J Obstet Gynecol Reprod Biol 2017;215:93-100.

40. Ryu CS, Sakong JH, Ahn EH, Kim JO, Ko D, Kim JH, et al. Association study of the three functional polymorphisms (TAS2R46G>A, OR4C16G>A, and OR4X1A>T) with recurrent pregnancy loss. Genes Genomics 2019;41:61-70.

41. Trowsdale J, Betz AG. Mother's little helpers: mechanisms of maternal-fetal tolerance. Nat Immunol 2006;7:241-6.

42. Schjenken JE, Zhang B, Chan HY, Sharkey DJ, Fullston T, Robertson SA. Mirna regulation of immune tolerance in early pregnancy. Am J Reprod Immunol 2016;75:272-80.

43. Saito $S$, Nakashima A, Shima T, Ito M. Th1/Th2/Th17 and regulatory T-cell paradigm in pregnancy. Am J Reprod Immunol 2010;63:601-10.

44. Kheshtchin N, Gharagozloo M, Andalib A, Ghahiri A, Maracy MR, Rezaei A. The expression of Th1- and Th2related chemokine receptors in women with recurrent miscarriage: the impact of lymphocyte immunotherapy. Am J Reprod Immunol 2010;64:104-12.
45. Nakagawa K, Kwak-Kim J, Ota K, Kuroda K, Hisano $M$, Sugiyama $R$, et al. Immunosuppression with tacrolimus improved reproductive outcome of women with repeated implantation failure and elevated peripheral blood TH1/TH2 cell ratios. Am J Reprod Immunol 2015;73:353-61.

46. Ota K, Dambaeva S, Han AR, Beaman K, GilmanSachs A, Kwak-Kim J. Vitamin D deficiency may be a risk factor for recurrent pregnancy losses by increasing cellular immunity and autoimmunity. Hum Reprod 2014;29:208-19.

47. Wegmann TG. Placental immunotrophism: maternal T cells enhance placental growth and function. Am J Reprod Immunol Microbiol 1987;15:67-9.

48. Li Y, Zhang J, Zhang D, Hong $X$, Tao Y, Wang S, et al. Tim-3 signaling in peripheral nk cells promotes maternal-fetal immune tolerance and alleviates pregnancy loss. Sci Signal 2017;10:eaah4323.

49. Motedayyen $H$, Rezaei $A$, Zarnani AH, Tajik N. Human amniotic epithelial cells inhibit activation and pro-inflammatory cytokines production of naive CD4+ T cells from women with unexplained recurrent spontaneous abortion. Reprod Biol 2018;18:182-8.

50. Tuomi T, Groop LC, Zimmet PZ, Rowley MJ, Knowles W, Mackay IR. Antibodies to glutamic acid decarboxylase reveal latent autoimmune diabetes mellitus in adults with a non-insulin-dependent onset of disease. Diabetes 1993;42:359-62.

51. Alecsandru D, Barrio A, Andia V, Cruz E, Aparicio P, Serna J, et al. Pancreatic autoimmunity: an unknown etiology on patients with assisted reproductive techniques (ART)-recurrent reproductive failure. PLoS One 2018;13:e0203446.

52. Pedicino D, Liuzzo G, Trotta F, Giglio AF, Giubilato S, Martini $F$, et al. Adaptive immunity, inflammation, and cardiovascular complications in type 1 and type 2 diabetes mellitus. J Diabetes Res 2013;2013:184258.

53. Yang Z, Zhou Z, Huang G, Ling H, Yan X, Peng J, et al. The CD4(+) regulatory T-cells is decreased in adults with latent autoimmune diabetes. Diabetes Res Clin Pract 2007;76:126-31.

54. Akesson C, Uvebrant K, Oderup C, Lynch K, Harris RA, Lernmark $A$, et al. Altered natural killer (NK) cell frequency and phenotype in latent autoimmune diabetes in adults (LADA) prior to insulin deficiency. Clin Exp 


\section{Obstetrics \& Gynecology Science}

Chang-Zhu Pei, et al. Pathogenetic factors with RPL

Immunol 2010;161:48-56.

55. Buzzetti R, Di Pietro S, Giaccari A, Petrone A, Locatelli $M$, Suraci $C$, et al. High titer of autoantibodies to GAD identifies a specific phenotype of adult-onset autoimmune diabetes. Diabetes Care 2007;30:932-8.

56. Ruuls SR, Sedgwick JD. Unlinking tumor necrosis factor biology from the major histocompatibility complex: lessons from human genetics and animal models. Am J Hum Genet 1999;65:294-301.

57. Majetschak M, Obertacke U, Schade FU, Bardenheuer M, Voggenreiter G, Bloemeke B, et al. Tumor necrosis factor gene polymorphisms, leukocyte function, and sepsis susceptibility in blunt trauma patients. Clin Diagn Lab Immunol 2002;9:1205-11.

58. Siwetz M, Blaschitz A, El-Heliebi A, Hiden U, Desoye $G$, Huppertz $B$, et al. TNF-a alters the inflammatory secretion profile of human first trimester placenta. Lab Invest 2016;96:428-38.

59. Chen G, Goeddel DV. TNF-R1 signaling: a beautiful pathway. Science 2002;296:1634-5.

60. Trussell J, Lalla AM, Doan QV, Reyes E, Pinto L, Gricar J. Cost effectiveness of contraceptives in the United States. Contraception 2009;79:5-14.

61. Said EA, Dupuy FP, Trautmann L, Zhang Y, Shi Y, El-Far $M$, et al. Programmed death-1-induced interleukin-10 production by monocytes impairs CD4+ T cell activation during HIV infection. Nat Med 2010;16:452-9.

62. Alijotas-Reig J, Llurba E, Gris JM. Potentiating maternal immune tolerance in pregnancy: a new challenging role for regulatory T cells. Placenta 2014;35:241-8.

63. Götestam Skorpen $C$, Hoeltzenbein M, Tincani A, Fischer-Betz R, Elefant E, Chambers C, et al. The EULAR points to consider for use of antirheumatic drugs before pregnancy, and during pregnancy and lactation. Ann Rheum Dis 2016;75:795-810.

64. Flint J, Panchal S, Hurrell A, van de Venne M, Gayed M, Schreiber $K$, et al. BSR and BHPR guideline on prescribing drugs in pregnancy and breastfeeding-part I: standard and biologic disease modifying anti-rheumatic drugs and corticosteroids. Rheumatology (Oxford) 2016:55:1693-7.

65. Alijotas-Reig J, Esteve-Valverde E, Ferrer-Oliveras R, Llurba E, Gris JM. Tumor necrosis factor-alpha and pregnancy: focus on biologics. An updated and comprehensive review. Clin Rev Allergy Immunol
2017; 53:40-53.

66. Kauma SW, Aukerman SL, Eierman D, Turner T. Colony-stimulating factor- 1 and c-fms expression in human endometrial tissues and placenta during the menstrual cycle and early pregnancy. J Clin Endocrinol Metab 1991;73:746-51.

67. Rahmati $M$, Petitbarat $M$, Dubanchet $S$, Bensussan $A$, Chaouat $\mathrm{G}$, Ledee N. Colony stimulating factors 1, 2, 3 and early pregnancy steps: from bench to bedside. J Reprod Immunol 2015;109:1-6.

68. Makinoda S, Hirosaki N, Waseda T, Tomizawa H, Fujii R. Granulocyte colony-stimulating factor (G-CSF) in the mechanism of human ovulation and its clinical usefulness. Curr Med Chem 2008;15:604-13.

69. Mielcarek M, Graf L, Johnson G, Torok-Storb B. Production of interleukin-10 by granulocyte colony-stimulating factor-mobilized blood products: a mechanism for monocyte-mediated suppression of T-cell proliferation. Blood 1998;92:215-22.

70. Sugita K, Hayakawa S, Karasaki-Suzuki M, Hagiwara H, Chishima F, Aleemuzaman S, et al. Granulocyte colony stimulation factor (G-CSF) suppresses interleukin (IL)-12 and/or IL-2 induced interferon (IFN)-gamma production and cytotoxicity of decidual mononuclear cells. Am J Reprod Immunol 2003;50:83-9.

71. Moldenhauer LM, Keenihan SN, Hayball JD, Robertson SA. GM-CSF is an essential regulator of T cell activation competence in uterine dendritic cells during early pregnancy in mice. J Immunol 2010;185:7085-96.

72. Wright EM, Ghezzi C, Loo DD. Novel and unexpected functions of sglts. Physiology (Bethesda) 2017;32:43543.

73. Faham S, Watanabe A, Besserer GM, Cascio D, Specht A, Hirayama BA, et al. The crystal structure of a sodium galactose transporter reveals mechanistic insights into Na+/sugar symport. Science 2008;321:810-4.

74. Salker MS, Singh $Y$, Zeng $N$, Chen $H$, Zhang S, Umbach AT, et al. Loss of endometrial sodium glucose cotransporter sglt1 is detrimental to embryo survival and fetal growth in pregnancy. Sci Rep 2017;7:12612.

75. Shibazaki T, Tomae M, Ishikawa-Takemura Y, Fushimi N, Itoh $F$, Yamada M, et al. KGA-2727, a novel selective inhibitor of a high-affinity sodium glucose cotransporter (SGLT1), exhibits antidiabetic efficacy in rodent models. J Pharmacol Exp Ther 2012;342:288-96. 


\title{
Obstetrics \& Gynecology Science
}

\author{
Vol. 62, No. 4, 2019
}

76. Sharma P, Khairnar V, Madunić IV, Singh Y, Pandyra A, Salker MS, et al. Sglt1 deficiency turns listeria infection into a lethal disease in mice. Cell Physiol Biochem 2017;42:1358-65.

77. Kitaya K, Takeuchi T, Mizuta S, Matsubayashi H, Ishikawa T. Endometritis: new time, new concepts. Fertil Steril 2018;110:344-50.

78. McQueen DB, Perfetto CO, Hazard FK, Lathi RB. Pregnancy outcomes in women with chronic endometritis and recurrent pregnancy loss. Fertil Steril 2015; 104:927-31.

79. Kitaya K, Yasuo T. Immunohistochemistrical and clinicopathological characterization of chronic endometritis. Am J Reprod Immunol 2011;66:410-5.

80. Cicinelli E, Matteo M, Trojano G, Mitola PC, Tinelli R, Vitagliano $A$, et al. Chronic endometritis in patients with unexplained infertility: prevalence and effects of antibiotic treatment on spontaneous conception. Am J Reprod Immunol 2018;79:e12782.

81. Metwally M, Preece R, Thomas J, Ledger W, Li TC. A proteomic analysis of the endometrium in obese and overweight women with recurrent miscarriage: preliminary evidence for an endometrial defect. Reprod Biol Endocrinol 2014;12:75.

82. Knochenhauer ES, Key TJ, Kahsar-Miller M, Waggoner W, Boots LR, Azziz R. Prevalence of the polycystic ovary syndrome in unselected black and white women of the southeastern United States: a prospective study. J Clin Endocrinol Metab 1998;83:3078-82.

83. Okon MA, Laird SM, Tuckerman EM, Li TC. Serum androgen levels in women who have recurrent miscarriages and their correlation with markers of endometrial function. Fertil Steril 1998;69:682-90.

84. Rahman TU, Ullah K, Guo MX, Pan HT, Liu J, Ren J, et al. Androgen-induced alterations in endometrial proteins crucial in recurrent miscarriages. Oncotarget 2018;9:24627-41.

85. Practice Committee of the American Society for Reproductive Medicine. Current clinical irrelevance of luteal phase deficiency: a committee opinion. Fertil Steril 2015;103:e27-32.

86. Amrane S, McConnell R. Endocrine causes of recurrent pregnancy loss. Semin Perinatol 2019;43:80-3.

87. Meresman GF, Olivares $C$, Vighi S, Alfie M, Irigoyen $\mathrm{M}$, Etchepareborda JJ. Apoptosis is increased and cell proliferation is decreased in out-of-phase endometria from infertile and recurrent abortion patients. Reprod Biol Endocrinol 2010;8:126.

88. Licht P, Fluhr H, Neuwinger J, Wallwiener D, Wildt L. Is human chorionic gonadotropin directly involved in the regulation of human implantation? Mol Cell Endocrinol 2007;269:85-92.

89. Fox C, Azores-Gococo D, Swart L, Holoch K, Savaris RF, Likes CE, et al. Luteal phase HCG support for unexplained recurrent pregnancy loss - a low hanging fruit? Reprod Biomed Online 2017;34:319-24.

90. Teichert A, Arnold LA, Otieno S, Oda Y, Augustinaite I, Geistlinger TR, et al. Quantification of the vitamin $D$ receptor-coregulator interaction. Biochemistry 2009;48:1454-61.

91. Shahbazi M, Jeddi-Tehrani M, Zareie M, SalekMoghaddam A, Akhondi MM, Bahmanpoor M, et al. Expression profiling of vitamin $D$ receptor in placenta, decidua and ovary of pregnant mice. Placenta 2011;32:657-64.

92. Grzechocinska B, Dabrowski FA, Cyganek A, Wielgos $M$. The role of vitamin $D$ in impaired fertility treatment. Neuroendocrinol Lett 2013;34:756-62.

93. Lemire JM, Adams JS, Sakai R, Jordan SC. 1 alpha,25dihydroxyvitamin D3 suppresses proliferation and immunoglobulin production by normal human peripheral blood mononuclear cells. J Clin Invest 1984;74:65761.

94. Piccinni MP, Scaletti C, Maggi E, Romagnani S. Role of hormone-controlled Th1- and Th2-type cytokines in successful pregnancy. J Neuroimmunol 2000;109:303.

95. Adams JS, Hewison M. Unexpected actions of vitamin $D$ : new perspectives on the regulation of innate and adaptive immunity. Nat Clin Pract Endocrinol Metab 2008;4:80-90.

96. Ji JL, Muyayalo KP, Zhang YH, Hu XH, Liao AH. Immunological function of vitamin $D$ during human pregnancy. Am J Reprod Immunol 2017;78:e12716.

97. Morales-Prieto DM, Chaiwangyen W, Ospina-Prieto $S$, Schneider U, Herrmann J, Gruhn B, et al. MicroRNA expression profiles of trophoblastic cells. Placenta 2012;33:725-34.

98. Bartel DP. MicroRNAs: target recognition and regulatory functions. Cell 2009;136:215-33. 


\section{Obstetrics \& Gynecology Science}

Chang-Zhu Pei, et al. Pathogenetic factors with RPL

99. Parveen F, Agrawal S. Recurrent miscarriage and micro-RNA among north Indian women. Reprod Sci 2015;22:410-5.

100. Fluhr H, Wenig H, Spratte J, Heidrich S, Ehrhardt J, Zygmunt M. Non-apoptotic fas-induced regulation of cytokines in undifferentiated and decidualized human endometrial stromal cells depends on caspase-activity. Mol Hum Reprod 2011;17:127-34.

101. Carcagno AL, Marazita MC, Ogara MF, Ceruti JM,
Sonzogni SV, Scassa ME, et al. E2F1-mediated upregulation of p19INK4d determines its periodic expression during cell cycle and regulates cellular proliferation. PLoS One 2011;6:e21938.

102. Jeon YJ, Choi YS, Rah H, Kim SY, Choi DH, Cha SH, et al. Association study of microRNA polymorphisms with risk of idiopathic recurrent spontaneous abortion in Korean women. Gene 2012;494:168-73. 